\title{
METHODOLOGY FOR SELECTION THE TRUCK ROUTE
}

\author{
Lilo Kunchev \\ Technical University - Sofia, Bulgaria \\ kunchev@tu-sofia.bg
}

\begin{abstract}
This study presents a methodology for selection the route of a truck moving between two points by taking into account multiple factors relevant to transport. The evaluation criteria have been selected so that they take account into the infrastructure road conditions, geographic characteristics of the road, roadside conditions and the weather conditions, on the one hand, and fuel consumption, on the other hand. The study examines four main sets of criteria with fifteenth sub-criteria. As sub-criteria related to the main criteria we have selected the condition of the road surface, the longitudinal and transverse unevenness of the road, inclines on the road, number of turns, restaurants and petrol stations, and others. The methods of Analytic Hierarchy Process (AHP) and Cost/Benefits have been applied. The AHP method has been used to determine the weights of the criteria and sub-criteria, and the priorities of alternative routes. The Cost/Benefits method has been applied for the selection of the best route of a truck among the alternatives under study. The methodology has been tried out on two variants taking into account the meteorological conditions. The results show that the criterions of the infrastructure road conditions are of great importance. Sub-criteria of great importance are the condition of the road surface, longitudinal and transverse lumpiness of the road, sections of the road under repair, category of road, availability of places to take a rest and parking lots. The decision approach proposed in this paper was tested for a route selection among alternatives for the road network in Bulgaria. The proposed model can help transport managers enhance the effectiveness of the movement of vehicles.
\end{abstract}

Keywords: AHP method, truck, transportation, route selection.

\section{Introduction}

Transport processes in automotive companies require the choice of a route, according to the condition of the roads for carriage the goods according to the season. It is necessary for managers of transport companies to take decisions in any situation. These decisions are often made intuitively, on the basis of their experience. To choose the route of the truck between two points it is necessary to adopt a complex approach, which will assess the objective criteria.

The multi-criteria decision-making approach Analytic Hierarchy Process (AHP) has been applied for best routes prioritization and selection. In [1;2] the authors have studied the problem of multiplecriteria selection of the transportation mode of cargo. The four main criteria characterizing the efficiency of freight transportation and the transportation system, such as the cost for cargo delivery, time of delivery, reliability of cargo transportation and ecological impact, have been defined by the authors. For route selection they have used the AHP method. In [3] the authors examine criteria such as costs, time, risk of freight damage, risk of infrastructure and equipment, risk of other factors for multimodal routes selection. In [4] the AHP method is used to choose the best alternative route through a study of the following criteria: risk of explosion or spill, risk of road accidents, consequences of an incident, travel time and travel cost. In [5;6] transport satisfaction, the average number of train stops, average distance travelled, average speed, reliability, availability of service with direct transport, transport capacity, direct operational costs and comfort have been chosen as the criteria for selecting the best variant scheme of transport. The combination of multi-criteria methods and the Cost/Benefits method to select the variant scheme of transportation is used in [5-8]. In [9] the multi-criteria route planning problem is studied. Using the AHP method, the travel distance, travel time, safety and fuel consumption criteria are prioritized. The maximum score has been obtained for fuel consumption (0.57), followed by security (0.29). The multiple-criteria method is used in [10], where three criteria for route choice (shipping time, shipping price, shipping safety) are applied. The AHP is also used in transportation research in [11].

The aim of this study is to employ a complex scientific approach for choosing the route of transportation of cargo by trucks and road trains. This objective is achieved by defining and ranking the criteria by means of the multi-criteria analysis method and the cost/benefit method for route selection. 


\section{Materials and methods}

The proposed methodology includes three steps. In the first step, the criteria and sub-criteria for evaluating the route of a truck have been chosen. In the second step, the AHP method has been applied to prioritise the criteria, sub-criteria and routes. The third step of the methodology includes a route selection by means of the Cost/Benefit ratio where the cost of each route is established through the fuel consumption and the benefits determined by the AHP method in the second step.

The following main groups of criteria have been considered:

- $\mathrm{C} 1$ - Infrastructure condition of the road

- $\mathrm{C} 2$ - Geographic conditions of the road

- $\mathrm{C} 3$ - Roadside amenities

- $\mathrm{C} 4$ - Impact of the meteorological conditions

The sub-criteria for main criterion $\mathrm{C} 1$ are:

- $\mathrm{C} 11$ - condition of the road surface.

That sub-criterion assesses road paving surface (asphalt) according to the years of exploitation up to 5 years, from 5 to 10 years and over 10 years. Irrespective of the quality of the pavement, with a period of exploitation of the asphalt paving of over 8 years and especially over 10 years, its rolling friction properties diminish, there are erosions of the surface with a depth of up to $10 \mathrm{~mm}$. That type of the road is not preferred by truck drivers because it is dangerous for transportation of heavy loads. The roads that are preferred are with asphalt paving with exploitation of up to 5 years.

- C12 - longitudinal and transverse lumpiness of the road. That sub-criterion takes into consideration bumps, holes and dips, which are bigger than $20 \mathrm{~mm}$. They lead to vertical disturbances, oblique-symetric exertion on the frames of the vehicles and high vertical acceleration, which require that speed of the vehicle is lowered.

- $\mathrm{C} 13$ - sections of the road under repair (number and length).

Irrespective of the type of road, sections under repair lead to narrowing the road and columns of vehicles form in the hours of heavy traffic. This causes lower average speed of driving, increases fuel consumption, and in some cases disrupts the term of delivery.

- $\mathrm{C} 14$ - signaling, safety barrier. This sub-criterion is important when driving on mountainous sections of the road, viaducts, night driving.

- $\mathrm{C} 15$ - control sections on the road (police, cameras, carrier control). The presence of traffic control makes drivers feel secure during the transportation process with regard to response in the case of road accidents, need for medical care, etc.

The sub-criteria for main criterion $\mathrm{C} 2$ are:

- C21 - category of road (motorway, intercity secondary road). Traffic on motorways is more reliable and the vehicles move more economically in terms of fuel consumption.

- $\mathrm{C} 22$ - displacement (declivities). That sub-criterion refers to descents and ascents while driving on the road which affects fuel consumption, and also is related to the skills of the driver.

- $\quad$ 23 - driving through settlements.

- C24 - number of turns with a radius of less than $1000 \mathrm{~m}$. That sub-criterion refers to dangerous turns in the road, which require special attention of the driver and lower speed of driving.

The sub-criteria for the main criterion $\mathrm{C} 3$ are:

- C31 - availability of places to take a rest and parking lots. These places are important because drivers need to take obligatory breaks after a certain number of hours of driving.

- $\mathrm{C} 32$ - petrol stations, number.

- C33 - environment, landscape. A lot of drivers prefer driving on a road with varied views. Most motorways are surrounded by an unvaried landscape.

The sub-criteria for main criterion $\mathrm{C} 4$ are: 
- C41 - cleaning, sanding. Cleaning and sanding are particularly important in winter conditions on icy roads and in snow drifts.

- C42 - signaling. This sub-criterion refers to the erection of warning signs and special signaling for road diversions, especially in winter conditions.

- C43 - availability of road assistance nearby.

The decision approach in the second phase of the methodology involves multi-criteria analysis. The Analytic Hierarchy Process (AHP) is one of the multiple criteria decision-making methods. The AHP method makes it possible to weigh both qualitative and quantitative data. It addresses the issue how to determine the relative importance of a set of activities. The AHP method is based on the following principles: the structure of the model; development of the ratings for each decision alternative for each criterion; synthesis of the priorities.

The first step is to make a pairwise comparison between the criteria. In the AHP, multiple pairwise comparisons are based on a standardized comparison scale of nine levels that is shown in Table 1, [12].

Table 1

Comparison Scale

\begin{tabular}{|c|c|}
\hline Intensely of importance & Definition \\
\hline 1 & Equal importance \\
\hline 3 & Moderate importance of one factor over another \\
\hline 5 & Strong or essential importance \\
\hline 7 & Very strong importance \\
\hline 9 & Extreme importance \\
\hline $2,4,6,8$ & Values for intermediate comparison \\
\hline
\end{tabular}

The result of the pairwise comparison of $n$ criteria can be summarized in an $(n, n)$ evaluation matrix in which every element $a_{i j}(i, j=1, \ldots, n)$ is the quotient of the weights of the criteria. The elements are assigned from Table 1.

The matrix elements have the following relationships:

$$
a_{i i}=1 ; \quad a_{i j} \neq 0 ; \quad a_{j i}=1 / a_{i j} .
$$

The second step in the AHP procedure is to normalize the matrix. The relative weights are given by the normalized right eigenvector $\left(W=\left\{w_{1}, \ldots, w_{n}\right\}^{T}\right)$ associated with the largest eigenvalue $\left(\lambda_{\max }\right)$ of the square matrix $A$ providing the weighting values for all decision elements. The largest eigenvalue $\left(\lambda_{\max }\right)$ can be calculated by using the following equation:

$$
\begin{gathered}
A W=\lambda_{\text {max }} \cdot W \\
\lambda_{\text {max }}=\sum_{i=1}^{n}\left[\left(\sum_{j=1}^{n} a_{i j}\right) \cdot W_{i}\right] .
\end{gathered}
$$

The third step calculates the consistency ratio and checks its value. The consistency ratio is found with the following formula:

$$
C R=\frac{C I}{R I} \leq 0.1,
$$

where $C I$-the consistency index;

$R I$ - random index.

The random matrix is given by Saaty, [12]. Its values are shown in Table 2. 
Random Consistency Index (RI)

\begin{tabular}{|c|c|c|c|c|c|c|c|c|c|c|c|c|c|c|c|}
\hline $\boldsymbol{n}$ & $\mathbf{1}$ & $\mathbf{2}$ & $\mathbf{3}$ & $\mathbf{4}$ & $\mathbf{5}$ & $\mathbf{6}$ & $\mathbf{7}$ & $\mathbf{8}$ & $\mathbf{9}$ & $\mathbf{1 0}$ & $\mathbf{1 1}$ & $\mathbf{1 2}$ & $\mathbf{1 3}$ & $\mathbf{1 4}$ & $\mathbf{1 5}$ \\
\hline $\mathrm{RI}$ & 0 & 0 & 0.58 & 0.9 & 1.12 & 1.24 & 1.32 & 1.41 & 1.45 & 1.49 & 1.51 & 1.48 & 1.56 & 1.57 & 1.59 \\
\hline
\end{tabular}

The consistency index is:

$$
C I=\frac{\lambda_{\max }-n}{n-1},
$$

where $\lambda_{\max }-$ the maximum eigenvalue of the priority matrix;

$n-$ the number of elements in the matrix.

In general, if the $C I$ is less than 0.10 , the consistency of the decision-maker is considered satisfactory but if the $C I$ exceeds 0.10 , some revision of the judgement may be required. In order to control the results of the methods, the consistency ratio $(C R)$ is used to estimate directly the consistency of pairwise comparisons.

The third step of the methodology includes a route selection by means of the Cost/Benefit ratio. The cost/benefit ratio is:

$$
r_{i}=\frac{c_{i}}{b_{i}} \rightarrow \min
$$

where $c_{i}-$ the normalized costs for the route $i$;

$b_{i}$ the AHP score for the route $i$;

$i=1, \ldots, m-$ the number of alternative routes.

The cost has been determined through the consumption of fuel, which is calculated using the data of the engines, costs and average speed in the different type of sections that have been tested in [13].

The minimal cost/benefit ratio presents the optimal route. The normalized costs present the proportion of the fuel costs for each of the variant routes.

$$
c_{i}=\frac{g_{i}}{\sum_{i=1}^{m} g_{i}},
$$

where $g_{i}-$ the fuel consumption for the route $i$ determined by [13].

\section{Results and discussion}

The methodology has been applied for the route from Sofia to Varna. This itinerary was chosen because there are five alternative routes between the starting and the final point and there is significant carriage of goods along it. Fig.1 shows the studied alternative routes.

In the research the transport processes have been divided into two variants:

- Variant 1 -Meteorological conditions in which the asphalt covering is clean and the air temperature is above $0^{0}$.

- Variant 2-Meteorological conditions with strong snow drifts and minus temperatures.

The paper uses the Super-Decision software, developed by William J. Adams of the Embry Riddle Aeronautic University, Daytona Beach in Florida and Rosanne W. Saaty of the Creative Decisions Foundation in Pittsburgh, [14]. The software helps structure and organize the comparisons, as well as to obtain and analyse the results. The software also calculates the consistency index (CI) of the judgements and makes the Graphical Sensitivity Analysis. A hierarchical decision model has a goal, criteria that are evaluated for their importance for the goal and alternatives that are evaluated for the level of preferences with respect to each criterion.

Fig. 2 presents the hierarchy model in Super Decision. 


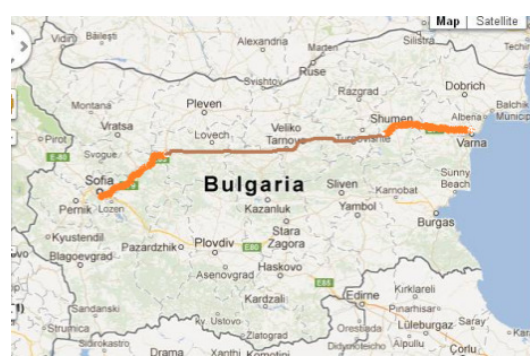

Map of route R1

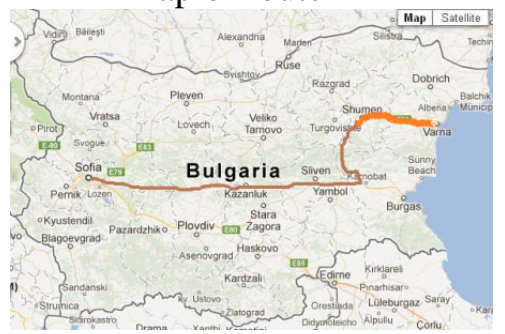

Map of route R4

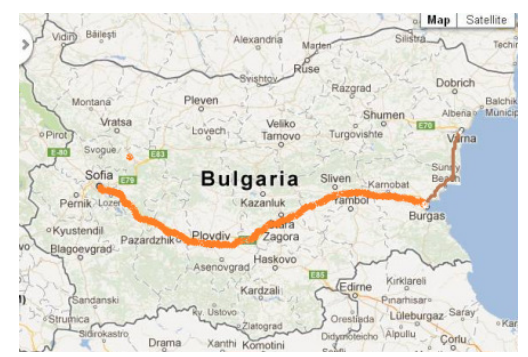

Map of route $\mathrm{R} 2$

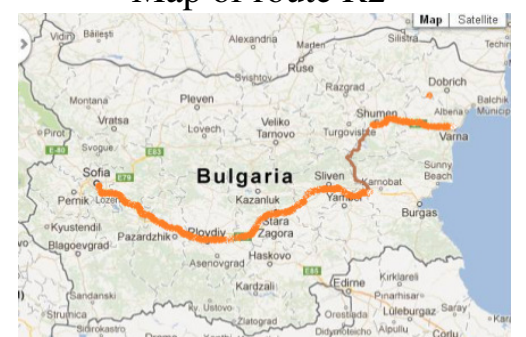

Map of route R5

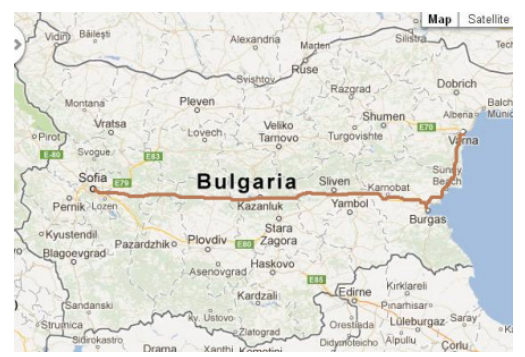

Map of route R3

With bold lines the motorways are set, and with a thin line - a secondary trunk road.

Fig. 1. Map of routes from Sofia to Varna

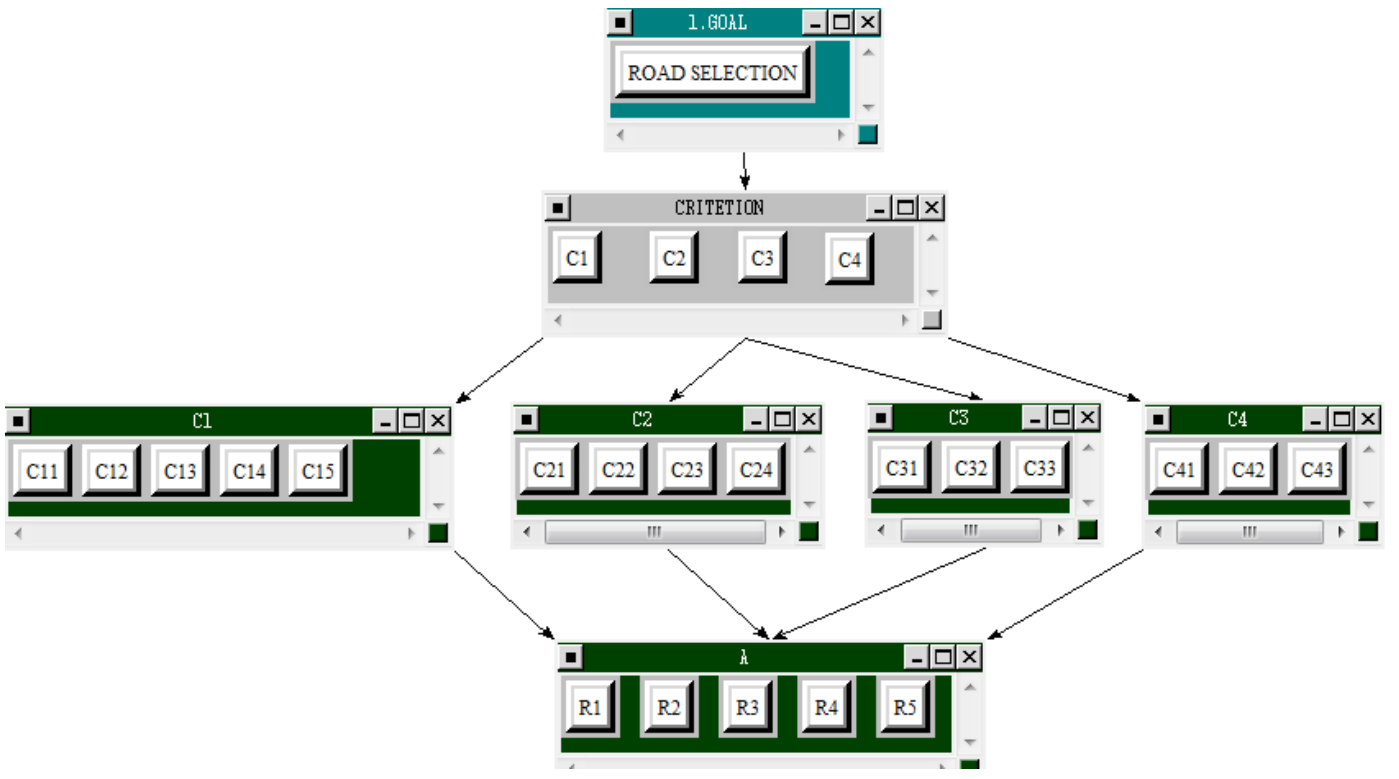

Fig. 2. Hierarchy model in Super Decision

The pairwise comparison of the criteria and sub-criteria is carried out by a group of eleven experts who gave an overall score along the scale of Saaty. Specialists with long experience in road transport, managers of transport companies and drivers have been chosen as experts. Tab.3, Tab.4 and Tab.5 show the prioritization matrixes and the results of weights by the AHP method. An example of prioritization matrix of the sub-criterion $\mathrm{C} 11$ is shown in Tab.6. The results of local and global weights of sub-criteria for both variants are shown it Tab.7. Fig. 3 presents the comparison of global weights of the criteria.

Table 3

Prioritization of criteria, weights

\begin{tabular}{|c|c|c|c|c|c|c|c|}
\hline Criterion & C1 & C2 & C3 & $\begin{array}{c}\text { C4 } \\
\text { Variant 1 }\end{array}$ & $\begin{array}{c}\text { C4 } \\
\text { Variant 2 }\end{array}$ & $\begin{array}{c}\text { Weight } \\
\text { Variant 1 }\end{array}$ & $\begin{array}{c}\text { Weight } \\
\text { Variant 2 }\end{array}$ \\
\hline $\mathrm{C} 1$ & 1 & 3 & 4 & 8 & $1 / 8$ & 0.538 & 0.161 \\
\hline $\mathrm{C} 2$ & $1 / 3$ & 1 & 2 & 8 & $1 / 8$ & 0.253 & 0.076 \\
\hline $\mathrm{C} 3$ & $1 / 4$ & $1 / 2$ & 1 & 8 & $1 / 8$ & 0.172 & 0.051 \\
\hline C4(Variant 1) & $1 / 8$ & $1 / 8$ & $1 / 8$ & 1 & 1 & 0.037 & - \\
\hline C4 (variant 2) & 8 & 8 & 8 & - & 1 & - & 0.712 \\
\hline
\end{tabular}


Prioritization of sub-criteria, weights

Table 4

\begin{tabular}{|c|c|c|c|c|c|c|c|c|c|c|c|c|}
\hline $\begin{array}{c}\text { Sub- } \\
\text { criterion }\end{array}$ & C11 & C12 & C13 & C14 & C15 & Weight & & C21 & C22 & C23 & C24 & Weight \\
\hline $\mathrm{C} 11$ & 1 & 2 & 2 & 2 & 3 & 0.282 & $\mathrm{C} 21$ & 1 & 3 & 5 & 5 & 0.575 \\
\hline $\mathrm{C} 12$ & $1 / 2$ & 1 & 3 & 3 & 3 & 0.339 & $\mathrm{C} 22$ & $1 / 3$ & 1 & 1 & 1 & 0.147 \\
\hline $\mathrm{C} 13$ & $1 / 2$ & $1 / 3$ & 1 & 3 & 3 & 0.194 & $\mathrm{C} 23$ & $1 / 5$ & 1 & 1 & $1 / 3$ & 0.101 \\
\hline $\mathrm{C} 14$ & $1 / 2$ & $1 / 3$ & $1 / 3$ & 1 & 3 & 0.100 & $\mathrm{C} 24$ & $1 / 5$ & 1 & 3 & 1 & 0.177 \\
\hline $\mathrm{C} 15$ & $1 / 3$ & $1 / 3$ & $1 / 3$ & $1 / 3$ & 1 & 0.085 & - & - & - & - & - & - \\
\hline
\end{tabular}

Prioritization of sub-criteria, weights

Table 5

\begin{tabular}{|c|c|c|c|c|c|c|c|c|c|c|c|c|c|}
\hline & \multicolumn{9}{|c|}{ Variant 1 and Variant 2 } & \multicolumn{6}{|c|}{ Variant 1 } & \multicolumn{4}{c|}{ Variant 2 } \\
\hline $\begin{array}{c}\text { Sub- } \\
\text { criterion }\end{array}$ & C31 & $\mathbf{C 3 2}$ & $\mathbf{C 3 3}$ & Weight & & C41 & $\mathbf{C 4 2}$ & $\mathbf{C 4 3}$ & Weight & $\mathbf{C 4 1}$ & $\mathbf{C 4 2}$ & $\mathbf{C 4 3}$ & Weight \\
\hline C31 & 1 & 3 & 3 & 0.594 & C41 & 1 & $1 / 2$ & $1 / 5$ & 0.128 & 1 & 9 & 1 & 0.338 \\
\hline C32 & $1 / 3$ & 1 & 2 & 0.249 & C42 & 2 & 1 & $1 / 2$ & 0.276 & $1 / 9$ & 1 & $1 / 9$ & 0.037 \\
\hline C33 & $1 / 3$ & $1 / 2$ & 1 & 0.157 & C43 & 5 & 2 & 1 & 0.596 & 1 & 9 & 1 & 0.337 \\
\hline
\end{tabular}

Prioritization of routes, weights

Table 6

\begin{tabular}{|c|c|c|c|c|c|c|}
\hline Sub-citerion C11 & R1 & R2 & R3 & R4 & R5 & Weight \\
\hline R1 & 1 & $1 / 3$ & 1 & 1 & $1 / 2$ & 0,125 \\
\hline R2 & 3 & 1 & 3 & 2 & $1 / 2$ & 0,279 \\
\hline R3 & 1 & $1 / 3$ & 1 & $1 / 2$ & $1 / 3$ & 0,099 \\
\hline R4 & 1 & $1 / 2$ & 2 & 1 & $1 / 2$ & 0,154 \\
\hline R5 & 2 & 2 & 3 & 2 & 1 & 0,343 \\
\hline
\end{tabular}

Local and global weights for sub-criteria

\begin{tabular}{|c|l|r|r|r|}
\hline \multirow{2}{*}{ Sub-criterion } & \multicolumn{2}{|c|}{ Variant 1 } & \multicolumn{2}{c|}{ Variant 2 } \\
\cline { 2 - 5 } & $\begin{array}{c}\text { Local } \\
\text { Weights }\end{array}$ & $\begin{array}{c}\text { Global } \\
\text { Weights }\end{array}$ & $\begin{array}{c}\text { Local } \\
\text { Weights }\end{array}$ & $\begin{array}{c}\text { Global } \\
\text { Weights }\end{array}$ \\
\hline C11 & 0.282 & 0.152 & 0.282 & 0.045 \\
\hline C12 & 0.339 & 0.182 & 0.339 & 0.055 \\
\hline C13 & 0.194 & 0.104 & 0.194 & 0.031 \\
\hline C14 & 0.100 & 0.054 & 0.100 & 0.016 \\
\hline C15 & 0.085 & 0.046 & 0.085 & 0.014 \\
\hline C21 & 0.575 & 0.145 & 0.575 & 0.043 \\
\hline C22 & 0.147 & 0.037 & 0.147 & 0.011 \\
\hline C23 & 0.101 & 0.025 & 0.101 & 0.008 \\
\hline C24 & 0.177 & 0.045 & 0.177 & 0.013 \\
\hline C31 & 0.594 & 0.102 & 0.594 & 0.031 \\
\hline C32 & 0.249 & 0.043 & 0.249 & 0.013 \\
\hline C33 & 0.157 & 0.027 & 0.157 & 0.008 \\
\hline C41 & 0.128 & 0.005 & 0.474 & 0.338 \\
\hline C42 & 0.276 & 0.01 & 0.053 & 0.037 \\
\hline C43 & 0.596 & 0.023 & 0.473 & 0.337 \\
\hline
\end{tabular}




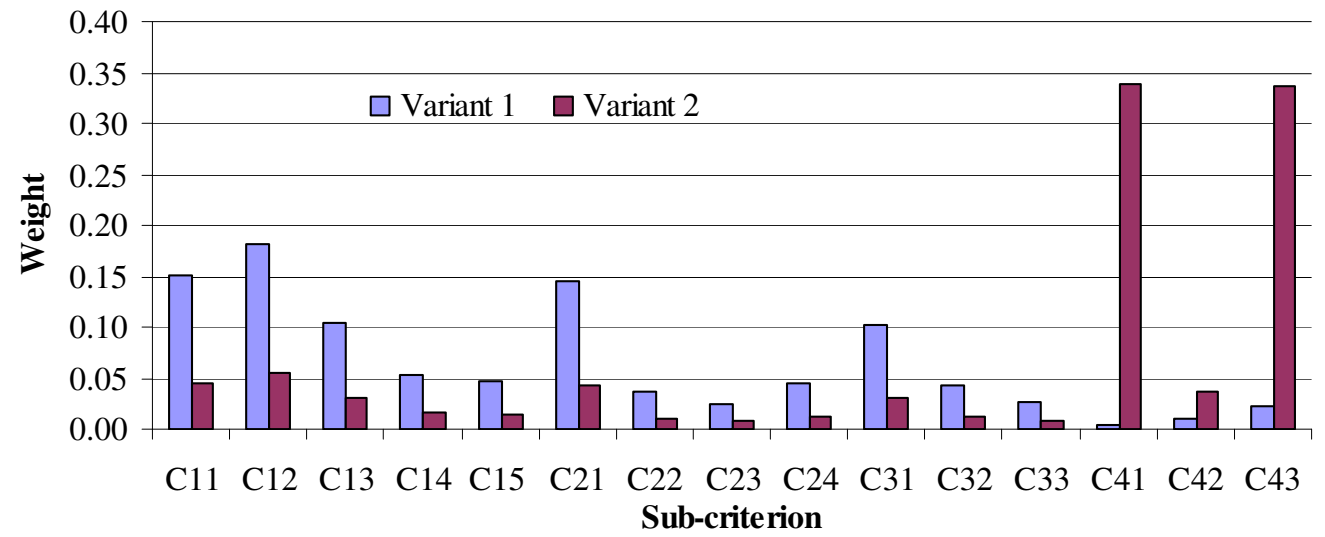

Fig. 3. Comparison of global weights of sub-criteria

The analysis of inconsistency (Consistency Ratio CR)makes it possible to measure how consistent the judgments have been accurate. If the CR is much in excess of 0.1 the judgements are unreliable and the evaluation must be repeated. Consistency applies only to the pairwise comparison matrices. It is desirable that the consistency is less than 0.10 . Table 7 shows the CR consistency measurements for the priorities. It can be seen that all CR have been satisfied, i.e. they are smaller than 0.1 .

Table 7

CR consistency measurements for the priorities

\begin{tabular}{|c|c|c|c|c|c|c|c|c|c|}
\hline Sub-criterion & $\mathrm{C11}$ & $\mathrm{C} 12$ & C13 & C14 & C15 & C21 & $\mathrm{C22}$ & $\mathrm{C} 23$ & $\mathrm{C24}$ \\
\hline $\mathrm{CR}$ & 0.029 & 0.013 & 0.003 & 0.100 & 0.007 & 0.012 & 0.051 & 0.038 & 0.010 \\
\hline Sub-criterion & C31 & C32 & $\mathbf{C 3 3}$ & $\mathrm{C41}$ & $\mathrm{C42}$ & $\mathrm{C43}$ & C31 & & \\
\hline $\mathrm{CR}$ & 0.050 & 0.019 & 0.017 & 0.003 & 0.042 & 0.003 & 0.050 & & \\
\hline Criterion & C1 & $\mathrm{C2}$ & $\mathrm{C3}$ & $\mathrm{C4}$ & & & & & \\
\hline $\mathrm{CR}$ & 0.041 & 0.07 & 0.05 & 0.005 & & & & & \\
\hline
\end{tabular}

Fig. 4 and Fig. 5 present the comparison of the routes according to the AHP score of each subcriterion for variant 1 and variant 2 . It can be seen that for the two variants the $\mathrm{R} 2$ route is the best by the AHP score on most of the sub-criteria. The R5 route is in the second position for variant 1 , for variant 2 the $\mathrm{R} 1$ route is in the second position.

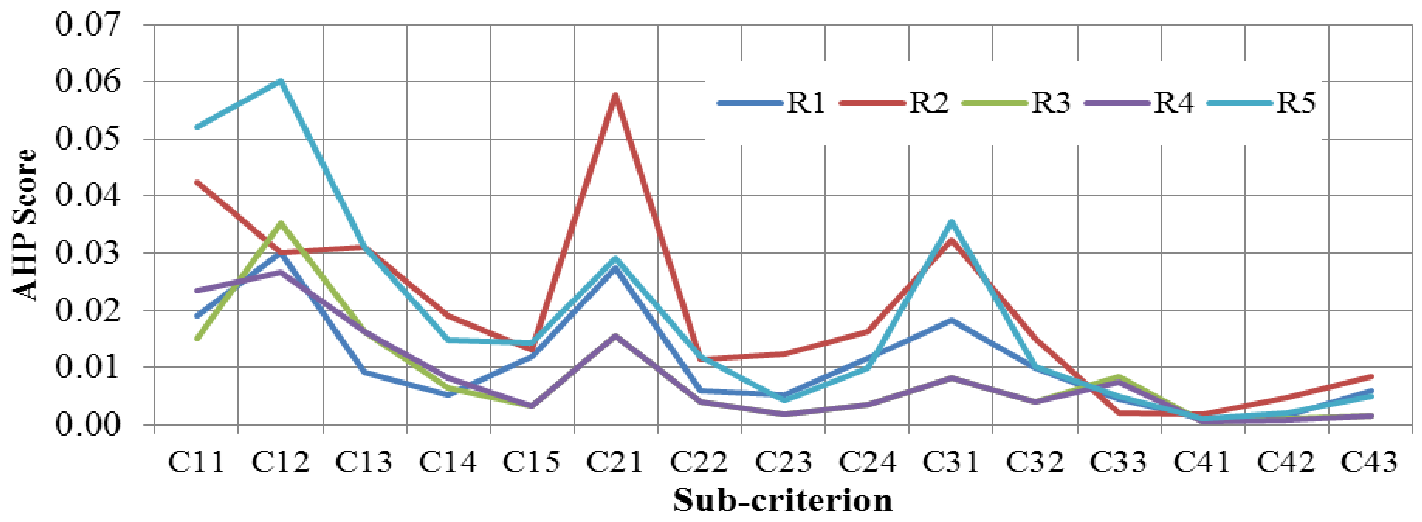

Fig. 4. Comparison of routes according to AHP score of each sub-criterion for Variant 1

The Super Decision software allows making a decision about the sensitivity of the results. The Graphical Sensitivity Analysis enables the researcher to adjust the priorities and to see the effect of changes in judgements on the overall ranking of the decision alternatives. The decision is remained unchanged for each change of the main criteria from 0 to $100 \%$. 


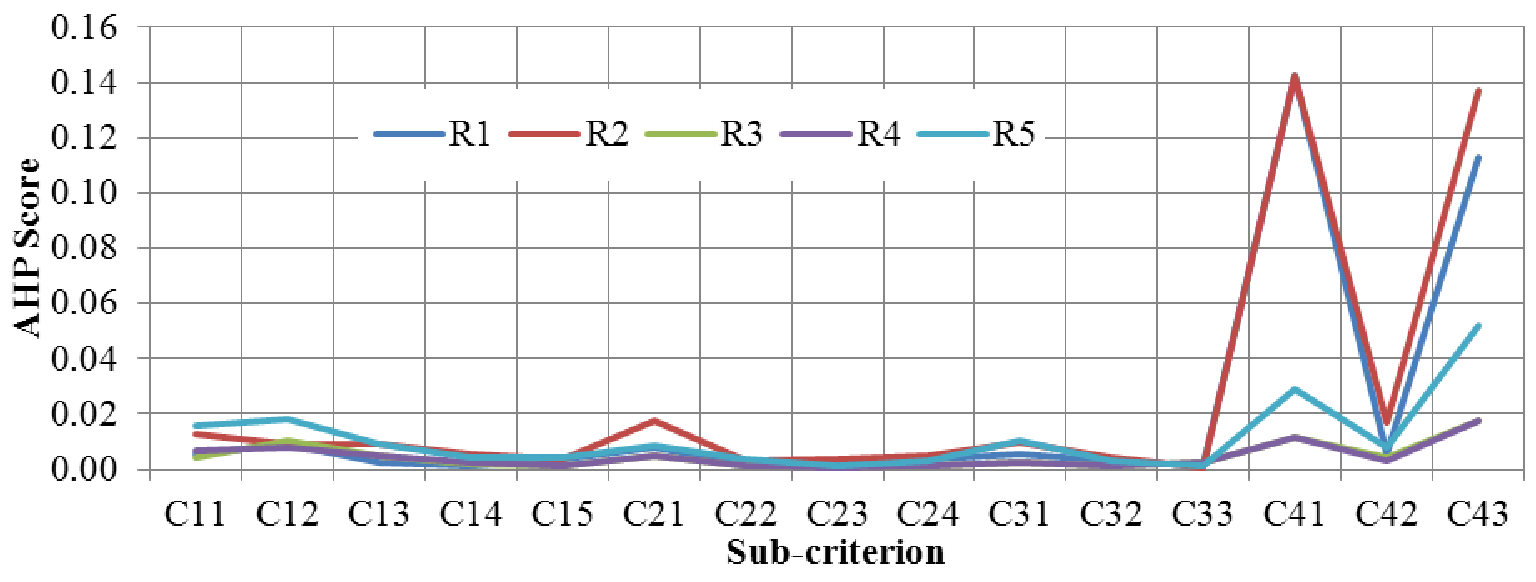

Fig. 5. Comparison of routes according to AHP score of each sub-criterion for Variant 2

The shortest path is R1, but the routes with minimum fuel consumption are R4 and R5. According to the AHP results, the road $\mathrm{R} 2$ is the best of all investigated roadways. Table 8 presents the results of the AHP score and the cost/benefits ratio. Fig.6 shows the results of the cost/benefits ratio for both variants.

Table 8

\section{Comparison of routes}

\begin{tabular}{|c|c|c|c|c|c|c|c|c|c|}
\hline \multirow[b]{2}{*}{ Route } & \multirow[b]{2}{*}{$\begin{array}{c}\text { Length, } \\
\text { km }\end{array}$} & \multirow{2}{*}{$\begin{array}{c}\text { Cost } \\
(\text { Fuel }) \\
\quad 1\end{array}$} & \multirow[b]{2}{*}{$\begin{array}{c}\text { Normalized } \\
\text { Cost }\end{array}$} & \multicolumn{3}{|c|}{ Variant 1} & \multicolumn{3}{|c|}{ Variant 2} \\
\hline & & & & $\begin{array}{l}\text { AHP } \\
\text { Score }\end{array}$ & $\begin{array}{c}\text { Cost/ } \\
\text { Benefits } \\
\text { Radio }\end{array}$ & Rating & $\begin{array}{l}\text { AHP } \\
\text { Score }\end{array}$ & \begin{tabular}{|c|} 
Cost/ \\
Benefits \\
Radio
\end{tabular} & $\mathbf{R a}$ \\
\hline R1 & 447 & 135.5 & 0.199 & .167 & 1.192 & 3 & 308 & 0.646 & 2 \\
\hline R2 & 531 & 162.3 & 0.238 & 0.298 & 0.800 & 2 & 0.381 & 0.624 & 1 \\
\hline R3 & 525 & 124.6 & 0.183 & 0.125 & 1.465 & 5 & 0.07 & 2.616 & 4 \\
\hline $\mathrm{R} 4$ & 530 & 124 & 0.182 & 0.124 & 1.460 & 4 & 0.069 & 2.640 & 5 \\
\hline R5 & 551 & 135 & 0.198 & 0.286 & 0.692 & 1 & 0.172 & 1.152 & 3 \\
\hline
\end{tabular}

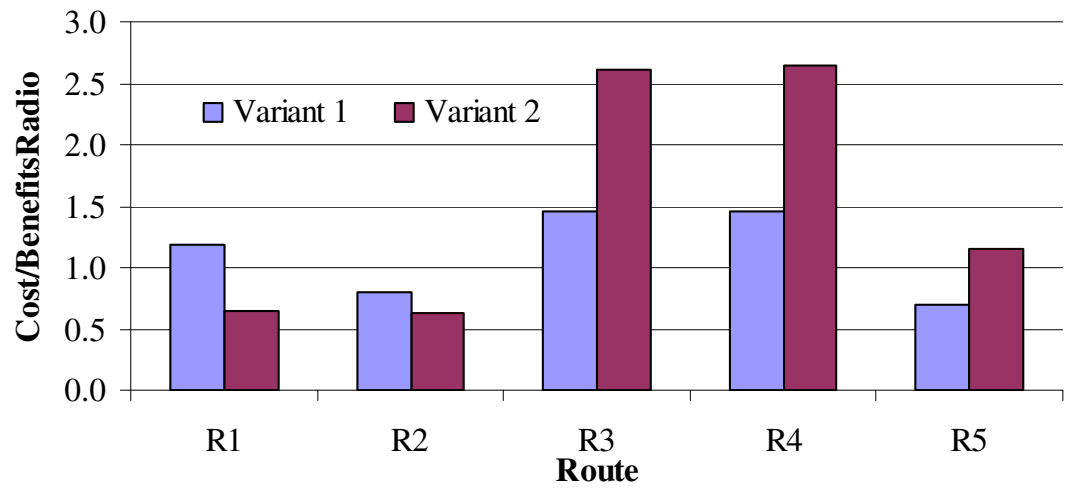

Fig. 6. Comparison of Cost/Benefits Radio

The research findings are as follows:

- The choice of the route depends on the meteorological conditions.

- The criteria, which greatly influence the decision in variant 1 , are those that take into consideration the condition and the type of the road - criterion $\mathrm{C} 1(54 \%)$ and the geographic conditions of the road - criterion $\mathrm{C} 2(26 \%)$. For variant 2 (winter) the criteria of greatest importance are seasonality - $\mathrm{C} 4(71 \%)$ and the road condition -C1 $(16 \%)$.

- Out of the sub-criteria of the $\mathrm{C} 1$ criterion (infrastructure condition of the road) those with the greatest influence are the sub-criteria C11 - condition of road surface $(34 \%)$ and $\mathrm{C} 12$ longitudinal and transverse lumpiness of the road $(28 \%)$. Out of the sub-criteria of the $\mathrm{C} 2$ 
criterion (geographic characteristics of the road) the one of the highest importance is C11 (57\%) - turns on the road. Out of the sub-criteria of the $\mathrm{C} 3$ criterion (roadside conditions) the one of the first importance is C31 (59\%) - availability of rest places and parking lots. Out of the sub-criteria of the $\mathrm{C} 4$ criterion (impact of the meteorological conditions) the one of the utmost importance is C41- signaling, safety barrier (59\%), which refers to availability of roadside assistance.

- The scores for the benefits of Variant1, achieved by using the AHPmethod, show similar results for R2 and R5 roads. The road with most advantages is R2.Road R2 is mostly a motorway, on which vehicles can run in a set regime - there is only a section of $125 \mathrm{~km}$ of secondary road. R2 is in the eastern part of the country, which is characterized by a temperate climate. For most of the year there are no extreme meteorological conditions, e.g. ice on the road or snowdrifts. In the section Burgas - Varna there are seven descents and ascents on that road, which makes R2 during summer not competitive to road R5, which has small displacement. Road R5 when compared with road R2 has approximately the same length of secondary road, but passes across a mountainous region and there are a great number of sharp turns on the road. For summer both roads are equivalent. In heavy snow drifts in winter road R5 is closed for traffic.

- The scores for the benefits of Variant 2, arrived at by using the AHP method, show similar results for roads R1 and R2. Road R1 is the main road in northern Bulgaria, has a good infrastructure, petrol stations and is maintained by competent bodies: traffic police and cargo transportation authority. Road R1 has about $280 \mathrm{~km}$ of second class motorway and passes through many settlements, which limits the driving speed and makes it difficult to make manoeuvres. On Road R2 for most of the year there are no extreme meteorological conditions, such as ice on the road or snow drifts.

- Using the Cost/Benefit method for Variant 1 we get road R5 as the best one followed by road R2. For Variant 2 the best roads are R2 and R1 as they are with similar results.

- The results are close to the real choice of the road made by drivers for the route studied here.

\section{Conclusions}

1. The study proposes criteria and sub-criteria to assess variant routes between two points.

2. A complex methodology for selection of an optimal route out of several alternatives has been developed. It consists of definition of criteria and sub-criteria, application of the method of Analytic Hierarchy Process and the method of Cost/ Benefit Analysis.

3. Criteria taking into account the meteorological conditions of transportation have been studied. This allows for the selection of a suitable route at any time of the year.

4. The criterion of the infrastructure road conditions (C1) is of great importance. It is in the first place for Variant 1, for Variant 2 it is the second.

5. Sub-criteria of great importance are C11- condition of the road surface (15\%), C12 - longitudinal and transverse lumpiness of the road (18\%), C13 - sections of the road under repair (10\%), C21 category of the road (14\%), C31- availability of places to take a rest and parking lots(10\%).

6. The methodology could be used to forecast the choice of the route.

\section{References}

1. Kopytov E., Abramov D. Multiple-criteria choice of transportation alternatives in freight transport system for different types of cargo.Proceedings of the "International Conference Reliability and Statistics in Transportation and Communication",2013,pp. 180-187.

2. Kopytov E., Abramov D. Multiple-criteria analysis and choice of transportation alternatives in multimodal freight transport system. Transport and Telecommunication, Vol.13(2), 2012, pp.148-158.

3. KengpolA., MeethomW., Tuominen M. The development of a decision support system in multimodal transportation routing within Greater Mekong sub-region countries, International Journal of Production Economics, Vol. 140 (2),2012, pp.691-701. 
4. Sattayaprasert W., Hanaoka S., Taneerananon P., Pradhananga R. Creating a risk-based network for hazmat logistics by route prioritization with AHP: Case Study: Gasoline Logistics in Rayong, IATSS Research, Vol.32(1), 2008, pp. 74-87.

5. Stoilova S., Nikolova R. A complex methodology for the study of intercity rail transport. Proceeding of "15th International Scientific Conference Engineering for Rural Development" 2527.05.2016, Jelgava, Latvia, pp.586-598.

6. Stoilova S., Nikolova R. Study of the scheme of transportation of intercity trains in the conditions of stochastic variation of passenger flows. Proceedings of International Conference on Electrical, Electronics, and Optimization Techniques (ICEEOT),3-5 March 2016,Tamil Nadu, India, pp.2657-2662.

7. Stoilova S. Study of the efficiency of motorail trains as a factor in transport development. Proceedings of the "3rd International Conference on Social Sciences \& Arts-SGEM" 24-31 August, 2016, Albena, Bulgaria, Book 2, Vol. 5, pp. 627-634.

8. Stoilova S., Nikolova R. Modeling and analysis of fast and express passenger railway transport using quantitative and qualitative indicators, Proceedings of the "Scientific conference on aeronauties, automotive and railway engineering and technologies, 16-18 September 2015, Sozopol, Bulgaria, pp.190-197.

9. Keser S. B.,Yazici A., Gunal S. A multi-criteria heuristic algorithm for personalized route planning. Anadolu University Journal of Science and Technology A-Applied Sciences and Engineering, Vol.17(2),2016, pp. 299 - 313.

10. Gursoy M. A method for transportation mode choice. Scientific Research and Essays, Vol.5(7), 2010, pp.613-624.

11. Xi J., Zhao Z., Li W.,Wang Q. A Traffic Accident Causation Analysis Method Based on AHP Apriori,Procedia Engineering, Vol. 137, 2016, pp.680 - 687.

12. Saaty T., Fundamentals of Decision Making and Priority Theory with the Analytic Hierarchy Process, RWS Publications, 2000.

13. European Truck Challenge ETC 2014, [online] [21.02.2017]. Available at: http://european-truckchallenge.com/downloads/etc-test-2014.pdf

14. Super Decisions Homepage. [online][21.02.2017]. Available at: http://www.superdecisions.com 